\title{
Behavioral Effects of Adrenal Medullary Transplants in Non-Human Primates
}

\author{
Mark Dubach \\ Department of Psychiatry and Behavioral Sciences \\ and \\ Regional Primate Research Center \\ University of Washington \\ Seattle, Washington, USA
}

\section{SUMMARY}

Small multiple "ribbon" autografts of intact adrenal medulla stereotaxically implanted at several sites throughout the striatum in longtailed macaques (Macaca fascicularis) have been shown to contain large amounts of viable glandular tissue as long as eight weeks after transplantation /15/. Variations of technique clearly influence viability $/ 12 /$. All monkeys were maintained in specially adapted rotometer cages $/ 30 /$ so that 24-hour measurements of activity and directional bias could be gathered. Lesions induced by intracerebral injection of 6-hydroxydopamine in the substantia nigra produced the expected chronic decrease in percentage of contralateral turning in most of the 24 subjects. Animals that received the longest viable ribbon grafts showed a reversal of this effect back toward base line, whereas monkeys whose grafts left little or no surviving tissue showed no behavioral improvement.

\section{KEY WORDS}

transplantation, adrenal medulla, monkey, parkinsonism, neostriatum, substantia nigra, CNS grafting

\footnotetext{
Reprint address:

Mark Dubach

Regional Primate Reseach Center

University of Washington SJ-50

Seattle, WA 98195, USA
}

\section{INTRODUCTION}

Rats with unilateral lesions created by intranigral injections of 6-hydroxydopamine (6OHDA) have commonly been used to assess behavioral effects of dopaminergic grafts, and rotation was the first behavior tested $/ 4,20 /$. It represents a global aspect of behavior, which can be measured simply and objectively. It is well established that after a few days, rodents usually rotate away from the side with the lesion when given apomorphine (attributed to ipsilateral receptor supersensitivity) and toward the side with the lesion when given amphetamine (attributed to contralateral transmitter release by intact neurons). For rodents, the rotometry model has been central to numerous studies of the phenomenology, pharmacology, and neuroanatomy of 6-OHDA effects $/ 27 /$, and, for rodents, it has a well-established sensitivity to the effects of fetal nigral and adrenal medullary grafts $/ 16 /$. For monkeys, this model is therefore a good starting point for examining the potential reversal of behavioral lesion effects by transplants.

For non-human primates, the literature on dopamine (DA) lesions and rotometry is much more limited. Early studies indicated that 6OHDA can produce nigral lesions with behavioral effects in marmosets and baboons /9,36/. More recent studies have tested the potential graft-induced reversal of rotational effects of unilateral lesions induced by unilateral intracarotid 
administration of $\mathrm{N}$-methylphenyltetrahydropyridine (MPTP) /2, 3, 8, 26, 37/.

In human hemiparkinsonian patients, spontaneous ipsilateral rotation has been documented $/ 6 /$, and spontaneous turning preference, as a naturalistic, quantitative aspect of clinical behavior, could be expected to provide a good model for animal testing. Rodent and non-human primate studies of graft effects, however, have focused on the acute response to the DA agonists apomorphine and amphetamine, rather than on spontaneous turning preference. These agonist models have been thoroughly studied in rodents, and the time course of agonist effects is well known; the models are very practical for making a few tests before and after transplants in large numbers of subjects. In monkeys, however, no models have been thoroughly studied, large samples are not an option, and various transplant methods and striatal placements are still being tested. The intensive study of a small number of monkeys is required for the development of transplant techniques, but the fewer the subjects, the less convincing and statistically efficient are a small number of drug tests in each subject at various times before and after transplantation. Repeated agonist treatments, furthermore, either require repeated, stressful transfers to and from special recording cages and equipment, or rely on visual observation.

The continuous measurement of spontaneous turning behavior in the home cage, on the other hand, permits the course of development of lesion and graft effects to be monitored in detail. A daily record constitutes a times series and enables the use of time series analysis for describing and testing the significance of graft effects in a single subject. For these reasons, continuous rotometry was selected as an initial behavioral model for the evaluation of transplants.

Several alternative mechanisms have been proposed to account for the effects of various types of DA implant in rodents and monkeys. Transplants have been reported to reverse the effects of lesions in rodents by local release of catecholamines from the grafts, either synaptically from fetal nigral graft processes reinnervating host striatal tissue /17/ or non-synaptically by shortrange diffusion from adrenal grafts $/ 19 \%$. A recent study has shown that an artificial implant of encapsulated DA, without any processes or synaptic contacts, is also capable of reversing lesion effects in rodents in the apomorphine rotometry model /38/. In monkeys, Watts et al. /37/ indicated that intraventricular adrenal autografts substantially reduced apomorphine-induced rotation over a survival period of several months, while unoperated controls showed no change over the same interval; recovery was greatest in monkeys with the largest numbers of surviving graft cells. Bankiewicz et al. /3/ reported that both adrenal allografts and control surgeries reduced apomorphine-induced rotation, due in part to a trophic effect on surviving host DA neurons; in two of three hemiparkinsonian monkeys that received fetal nigral grafts, apomorphine-induced circling was greatly reduced, an effect attributed again to a trophic effect encouraging the sprouting of host DA fibers, rather than to the direct release of catecholamines from the grafts $/ 26 /$.

The present study was designed to address issues of technique, effectiveness, and mechanism for adrenal grafts in monkeys, by using: (1) a less invasive transplant method to reduce the potential trophic effects of the open surgical procedure itself; (2) a more precise rotometry method to provide a full account of effects of lesion and transplant; (3) 24-h monitoring of spontaneous turning to eliminate interpretational problems associated with apomorphine and amphetamine testing; (4) time series analysis to allow each subject to be its own control; (5) behavioral evaluation of all animals studied; (6) quantitative comparison of three different measures extracted from the rotometry data to determine which is most sensitive to lesion and transplant effects. The focus on adrenal grafts was in part due to a view toward clinical use of autologous adrenal tissue which is less controversial than that of fetal donor tissue, and in part due to the experimental advantage of using the tissue source that for monkeys is more readily available.

The estimated number of surviving graft cells within the host striatum in 24 animals ranged from zero to more than 10,000 , and the number of striatal sites containing viable cells ranged from zero to nine (Dubach /12/: Table 3). The primary hypothesis of this study was that the animals with 
greater numbers and wider distributions of viable striatal cells would show the greater behavioral effects.

\section{MATERIALS AND METHODS}

\section{Subjects}

Subjects were 24 young adult male longtailed macaques (Macaca fascicularis) for which histology and graft techniques have previously been described $/ 11,12,15 /$. Monkeys were housed in Group III cages, 1 to 3 to a room, and, because behavioral monitoring proceeded 24 hours a day, were visually isolated from one another to avoid interaction that might be biased by the arrangement of cages or by the introduction and removal of companions from the room.

\section{Lesions and Transplants}

DA neurons in the substantia nigra were destroyed by local intracerebral injections of 6OHDA throughout the structure on one side. Early adrenal medullary grafts were prepared from diced tissue by various means (A1-B4); later grafts were prepared as ribbons cut from the intact gland $(5-10 \mathrm{~mm}$ long by $0.4-1.0 \mathrm{~mm}$ thick), and were placed vertically in and above the caudate and putamen nuclei (B9-B15). Lesion and transplant methods have been described previously in detail $/ 11,12,14,15 /$.

Early variations in the lesion method included 6-OHDA injections along only three tracks for monkeys A1-A3, while the fourth track to the posterior portion of substantia nigra was added for all other monkeys. The lesions in monkeys A1-B8 were created via a surgically implanted cranial platform $/ 10 /$, while those in monkeys B9-B15 were created directly in surgery under anesthesia, without a platform. Platforms permitted extra 6OHDA sessions for early monkeys (A1, A2, A3, A9, B2) before the method was standardized (Fig. 1a).

\section{Rotometry}

Each monkey was fitted with a jacket and a flexible cable tether in its home cage /25/. The tether was attached to a rotometer that reported to an IBM-XT computer in another room $130 /$. Several modifications and extensions have since been made in the apparatus. (1) The sensor unit, originally a potentiometer reporting to an A-D conversion board in the IBM-XT computer, was replaced with an optical encoder (HEDS-5500 F06; Hewlett Packard, San Jose CA), a more reliable device that has no dead-space position and provides digital output at a higher resolution (256 radial positions). A box containing a separate circuit board designed and built at the Regional Primate Research Center polled six encoders several hundred times per second, continually making their positions available to the computer, through a serial COM port. The "ROTOMETR" program checked the port 13-15 times per second, updating a record of each of six monkeys' positions. (2) A small hand-held keyboard (Psion Organizer II, Psion Inc., Watertown CT) was connected to the circuit-board box in the rotometer room for entering the monkey number and treatment each time a monkey was given a drug or taken to surgery. Treatment times were thus recorded in a standard, computer-accessible format, in synchrony with the computer clock timing the rotometry record. (3) The ROTOMETR program was expanded to save an additional file for each half-hour. In this file, movements were compiled into timed "events"; each event was assigned to one of four categories, either continual movement in one direction, gradual drift in one direction, wavering without net movement, or motionlessness. The boundaries between these event categories were established empirically before event recording was instituted, by review of on-line data samples from two early subjects, and were not changed thereafter throughout the experiments; boundaries were selected to preserve a fine-grained account of turning without requiring excessive disk space and processing time. On the basis of the event record, off-line software summed turns in each direction over 24-h intervals, expressing the total in units of $360^{\circ}$ circuits. 
The summation process depended on applying a definition of a "turn" to the fine-grained event record. Most of the data presented below were summed by defining a turn as any set of consecutive events that moved the rotometer to a threshold $90^{\circ}$ or further from its starting point; its starting point was then reset at the point where the last event terminated. The magnitude of each "turn" was thus 0.25 full circuits or more, and the threshold was updated with each such turn; this definition was designated "quarter dynamic" (QD). An alternative definition, applied to the same event record and designated "four-quarter fixed" (4QF), was any set of consecutive events that moved the rotometer in the same direction past four fixed points $90^{\circ}$ apart, without re-crossing any of the points in the opposite direction. The magnitude of each turn was thus recorded as 1 , for any actual excursion between 0.75 and 1.25 circuits. The sum of turns was expressed in full-circuit units for $4 \mathrm{QF}$, as for QD. The QD definition was selected because it reflects total activity as well as turning preference. The $4 \mathrm{QF}$ definition was selected in part because it simulates a definition commonly used in other studies; it also provides better resolution for the measurement of turning preference, although it reflects total activity less accurately than QD. Software options allow other definitions of a turn to be applied, but these are the only ones for which data are presented in this report. Options also allowed summing over intervals of other lengths, including the 9-min intervals used for data on apomorphine and amphetamine treatments presented below. (4) Because of the large size of event files, data were transferred daily, over a Desk-Link connection (Traveling Software, Bothell WA), to an 80386 computer with a 320 megabyte fixed disk (Dell Computer Corp, Austin TX). (5) Custom software was developed and compiled in PowerBASIC (SPECTRA Publishing, Sunnyvale CA). This software was used to reformat data files for off-line processing, to interface data files with treatment times, to document intervals for which data were missing, to extract consecutive blocks of data from the event file to match selected time intervals and turning thresholds, and to assemble data in files consisting of 50 pre-treatment and 150 post-treatment intervals.

\section{Statistical Evaluation}

Studies were initiated with the view that a good transplant method for non-human primates was not yet known, and that histological evidence would provide a much more direct evaluation of innovative transplant methods than behavioral testing. The development of a quantitative behavioral assay for the later stages of these studies, however, was a primary goal. A statistical appraisal of rotometry data for single subjects was necessary, because any one variation of method could be tested in only one or a few subjects. Sample sizes have been small in primate transplant studies. Aside from the 24 subjects of the present study, behavioral effects of adrenal grafts have been reported for a total of only 16 monkeys receiving adrenal grafts $13,26,37 /$. Sample sizes will continue to be small, moreover, until outstanding implant techniques and an appropriate distribution of target sites are well understood and can be tested critically in a large sample. A statistical method should appraise behavioral results, much as immunohistochemistry can appraise graft viability, in the individual subject. The serial data at regular intervals that are provided by 24 -h rotometry permit the application of time series analysis, which is just such a method. The widely used Autoregressive Integrated Moving Average (ARIMA) method /5, 21, 24, 39/ was applied to the data, and statistical calculations were performed by the Statistical Package for the Social Sciences 129/. Details of this method are presented elsewhere /13/. For practical and experimental reasons during the development of transplant and rotometry methods, pre-lesion and lesion periods were often too short to allow inferential use of time series analysis. Nevertheless this analysis provided the best available method for characterizing the changes in turning behavior induced by the lesion and, subsequently, the transplant. In series for which all time series models were rejected because not enough data were available, the levels two standard deviations above and below the mean of available data were projected as confidence intervals (Fig. 1-7).

The analysis was applied to the series of data points preceding a treatment to generate confidence limits for subsequent turning in lesion and 
transplant periods; for the lesion period, time series analysis was applied to pre-lesion base-line data, and for the transplant period, analysis was applied to data from the lesion period. Within the analyzed series, the first days on the rotometer or the first days after the lesion were often unrepresentative for either total activity or turning preference (dashed lines on plots in Figures 1-5), and were omitted from the time series analysis for all three measures. Days for which data were incomplete or non-existent (gaps on plots), because of recovery from surgery, testing and development of software, or equipment failure, were also excluded from analysis; SPSS ARIMA routines automatically accommodate missing intervals. On the basis of the results, predicted values for future points were projected, along with upper and lower confidence intervals. Data points after the treatment (lesion, transplant, or drug administration) either lay largely within these confidence intervals, indicating no effect, or passed beyond them, indicating an effect. ARIMA is also capable of providing intervention analysis, which can estimate a significance level for data subsequent to the intervention, but this requires a priori knowledge of the onset time of treatment effects. This was not available for the present data, although it can be estimated for future experiments on the basis of these data.

Rotometry data for analysis consisted of the accumulated daily number of turns in the direction contralateral to the lesion ("contralateral turns"), the total number of turns in either direction ("total activity"), and the percentage of total activity represented by contralateral turns ("turning preference"). Each monkey's rotometry record was divided into three parts, which varied considerably in length among animals. These parts were a "pre-lesion" period (2-50 days), a "lesion" period after the lesion and before the transplant (8-77 days), and a "transplant" period from the transplant to necropsy (8-56 days). The effects of lesion and transplant treatments were evaluated separately for each animal.

\section{RESULTS}

Records of spontaneous turning preference, contralateral turning, and total activity are displayed for all 24 monkeys (Fig. 1-3), arranged to facilitate comparison of the three measures for each animal. Expectations were (1) that base-line behavior of each monkey would display a stable level of asymmetry; (2) that the lesion, usually placed contralateral to the direction preferred by the animal in the pre-lesion period, would decrease contralateral turning preference; and (3) that transplants, if viable and properly distributed, would restore contralateral turning preference toward pre-lesion levels.

\section{Base-line Behavior}

Base-line turning preference was fairly consistent for each monkey. The magnitude of variability among samples can be expressed as the coefficient of variation (sample standard deviation/sample mean) $/ 31 /$, a statistic that is independent of the level of the mean and can therefore be used for comparing variability among widely ranging samples. Coefficients of variation for turning preference in the intact monkeys averaged $8 \%$ (range: $1 \%$ to $17 \%$ ). Among monkeys, on the other hand, base-line behavior was highly variable. The mean strength of turning preference ranged from $50 \%$ to $98 \%$ turning in the preferred direction, and the coefficient of variation among these sample means was $21 \%$.

The absolute number of turns in the preferred direction was much more variable, within subjects, (average coefficient of variation $34 \%$, range $5 \%$ to $100 \%$ ) because total activity varied from day to day. The mean number of turns in the preferred direction varied among monkeys even more, with means from 24 to 1656 turns per 24 hours, and the coefficient of variation among these means was $125 \%$.

\section{Lesion Effects}

The effect of the lesion on contralateral turning preference was usually a reduction (Fig. 1a-3a), over a period ranging from 1-2 days (e.g., A1, B11, B12) to 3 weeks (e.g., B2, B4); at least one monkey (A7) probably received a graft before the lesion had taken full effect. After this unpredictable onset phase, no spontaneous recoveries were ob- 

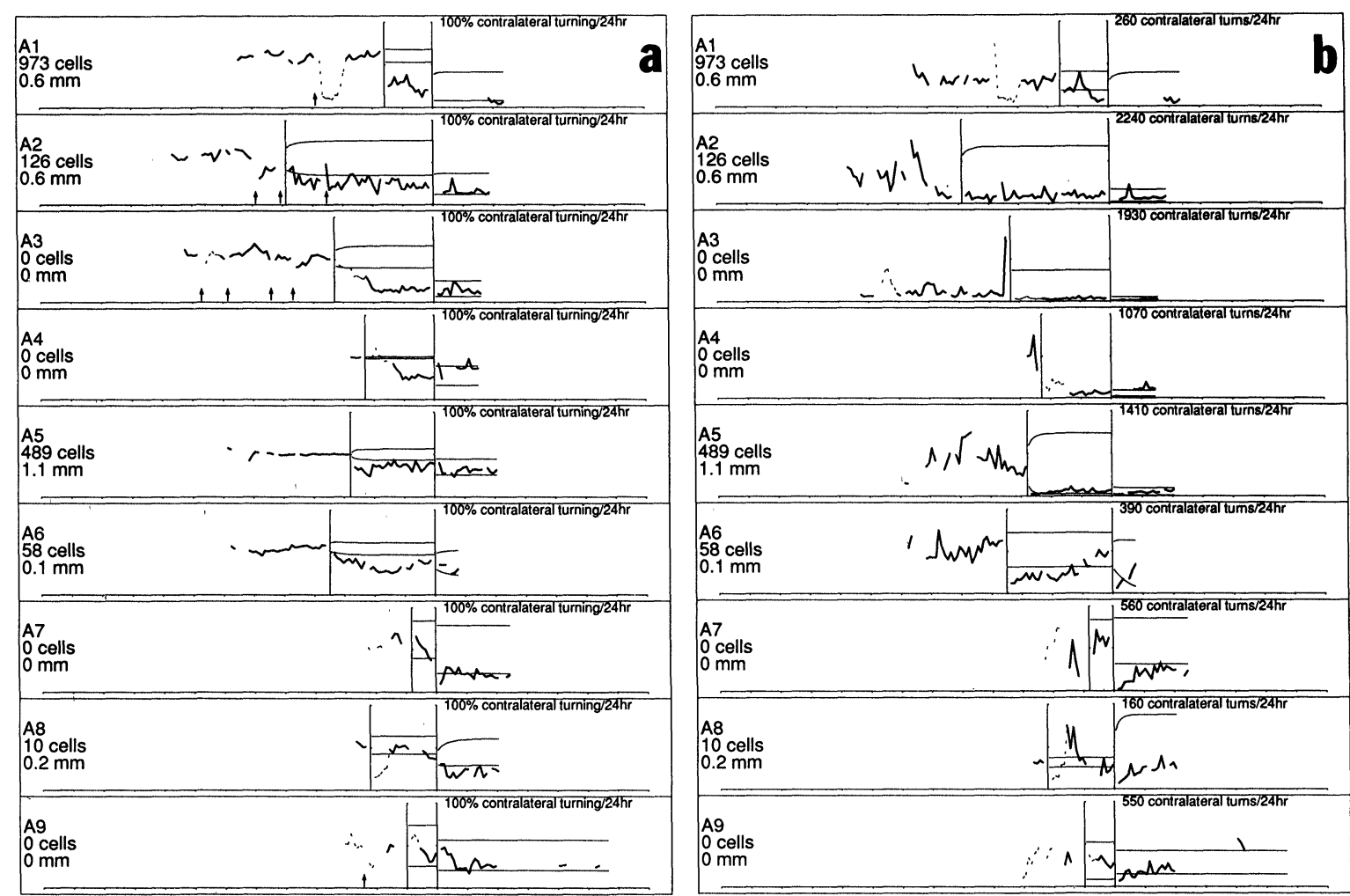

Fig. 1: a. Turning preference: A chart for each monkey A1-A9 displays contralateral turns as a percentage of total turning ( $y$-axes: $1 \mathrm{div}=50 \%$ ) for each 24-h interval ( $x$-axis: 1 div $=10$ days) before and after the times of the lesion (left $y$-axis) and the transplant (right $y$-axis). Thin horizontal lines to the right of each y-axis (lesion and transplant periods) represent the $95 \%$ confidence interval projected by an ARIMA analysis of values to the left of that $y$-axis (pre-lesion and lesion periods, respectively). (Lower confidence levels less than zero are omitted.) Early days of erratic behavior, just after placement in the rotometer cage or just after the 6-OHDA lesion, were omitted from the analysis but appear on the charts as dotted lines. Whether omitted because of erratic turning preference or total activity, such days were omitted from all three graphs. Label to the upper right indicates the maximum value on the $y$-axes, always $100 \%$ for turning-preference charts. Numbers to the left identify the monkey and give the estimated total number of viable grafted cells and summed lengths of viable graft segments at all sites (Dubach /12/: Table 3). Monkeys A1-A9 and B1-B15 (Fig. 2-3) are arranged in chronological order of testing. 6-OHDA concentration was $8 \mu \mathrm{g} / \mu \mathrm{l}$ for most treatments except $\mathrm{A} 1(4 \mu \mathrm{g} / \mu \mathrm{l})$ and $\mathrm{A} 2(1.5 \mu \mathrm{g} / \mu \mathrm{l})$. Additional treatments (arrows) were made at 1.5 $\mu \mathrm{g} / \mu \mathrm{l}$ (A1 first treatment, A2 first and second, A3 first and second), $4 \mu \mathrm{g} / \mu \mathrm{l}$ (A2 final, A3 third), and $8 \mu \mathrm{g} / \mu \mathrm{l}$ (A3 fourth, A9 first). Transplants in A1-A9 were made in the form of minced or diced tissue. For $A 1$ and $A 3$, erratic intermediate days associated with these early treatments were omitted from analysis and appear as dashed lines.

b. Contralateral turns: A chart for each monkey A1-A9 displays contralateral turns, based on the QD definition (see Methods), using the same format as Fig. 1a. Label to the upper right indicates the maximum value on the $y$-axes, which varies from one monkey and chart to another; division mark on y-axes is set at half that value. 
served over lesion periods up to 10 weeks, although in a few cases turning preference passed the pre-lesion lower confidence interval on a few occasions.

Turning preference was reduced by various amounts, from 97 percentage points (B11) to 7 percentage points (A8). In two monkeys (B1 and B14), the lesion had the opposite effect: it paradoxically increased turning to the contralateral direction. The paradoxical effect, which is analogous to paradoxical effects reported for rodent rotometry models, has been observed in approximately $20 \%$ of all monkeys with 6-OHDAinduced lesions (Dubach, unpublished). Following the common practice in rodent studies by which only animals with distinct behavioral effects of lesions are used for further testing, such monkeys generally were not used as adrenal graft recipients.

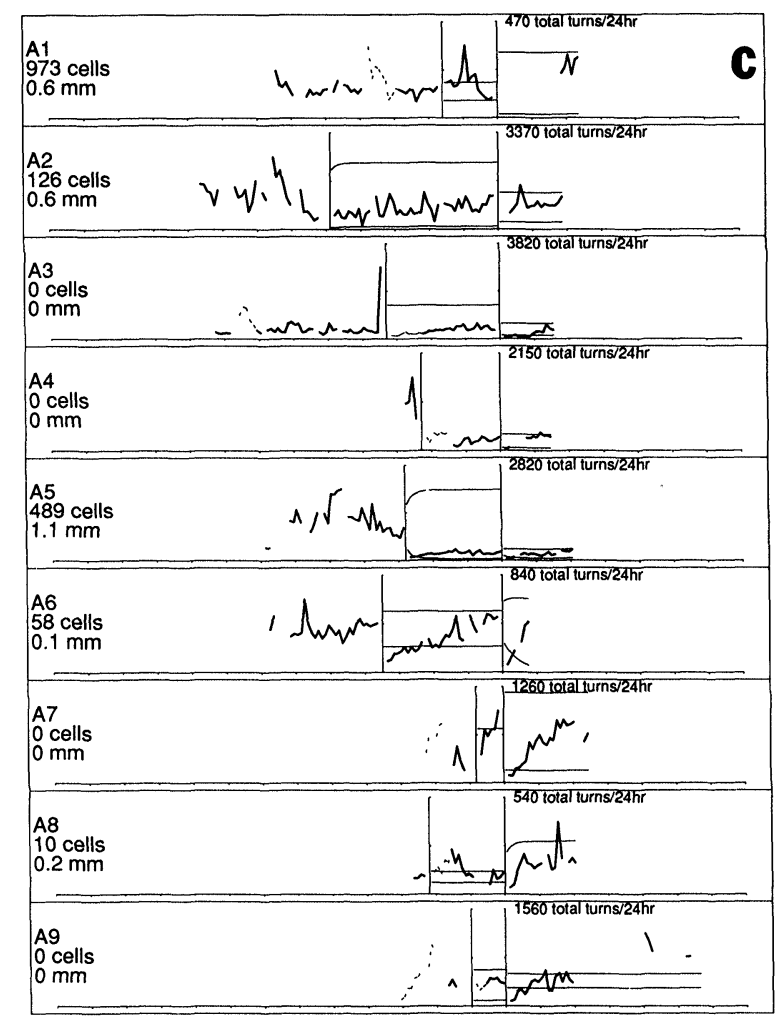

Fig. 1: c. Total activity: $A$ chart for each monkey $A 1-A 9$ displays total activity (contralateral plus ipsilateral turns), based on the QD definition (see Methods), using the same format as Fig. 1b.
The absolute number of contralateral turns, which reflects total activity as well as turning preference, was also reduced by lesions in most monkeys (Fig. 1b-3b), but effects were manifested less distinctly by this measure than by turning preference. No consistent effect was manifest in the total activity measure; it decreased in some animals, but was unaffected or even increased in others (Fig. 1c-3c).

Mean values before the lesion for each monkey were compared with mean values after the lesion. Paradoxical responders B1 and B14 were omitted from the analysis, and unrepresentative data immediately following lesions (dashed lines, Fig. 13 ) were excluded. Results indicated that lesions had a highly significant effect on both turning preference (2-tailed paired t-test, $\mathrm{p}<0.001)$ and number of contralateral turns $(p=0.006)$. An additional analysis compared the 16 monkeys that received non-ribbon grafts to the 6 that received ribbon grafts, considering the difference between mean values before and after the lesion for each monkey; the 6 monkeys that later received ribbon grafts experienced a significantly greater change in turning preference $(\mathrm{p}<0.001)$, but not in number of contralateral turns.

\section{Transplant Effects}

Adrenal grafts made by the ribbon method partially reversed the lesion effect on turning preference in 4 of 6 monkeys with normal lesion effects (Fig. 3a: B11, B12, B13, and B15). Grafts made by earlier methods, which resulted in much less surviving tissue (A1-A9; B2-B8), and ribbon grafts in the first two monkeys that received them (B9 and B10), had no beneficial effect. In fact, they often reduced contralateral turning even further. Monkeys B1 and B14 were excluded from consideration because their paradoxical responses to the lesion make the behavioral effects of transplants uninterpretable.

The contralateral turns measure (Fig. 3b) displayed similar effects. Total activity was unaffected by the transplants (Fig. 3c).

T-tests like those described above for lesion effects indicated that grafts of all kinds, considered together, had no significant effects, but that taking non-ribbon grafts as surgery controls, 

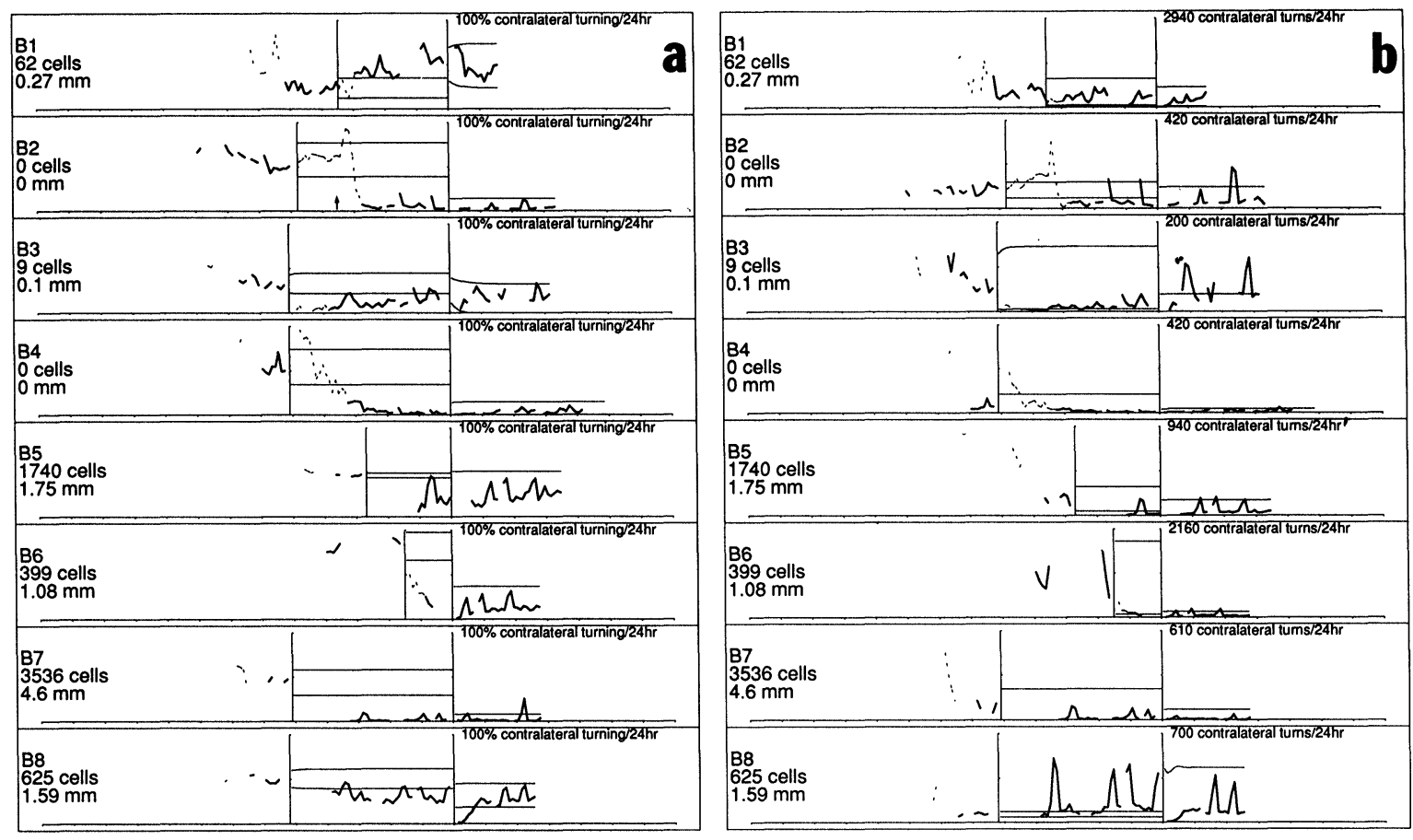

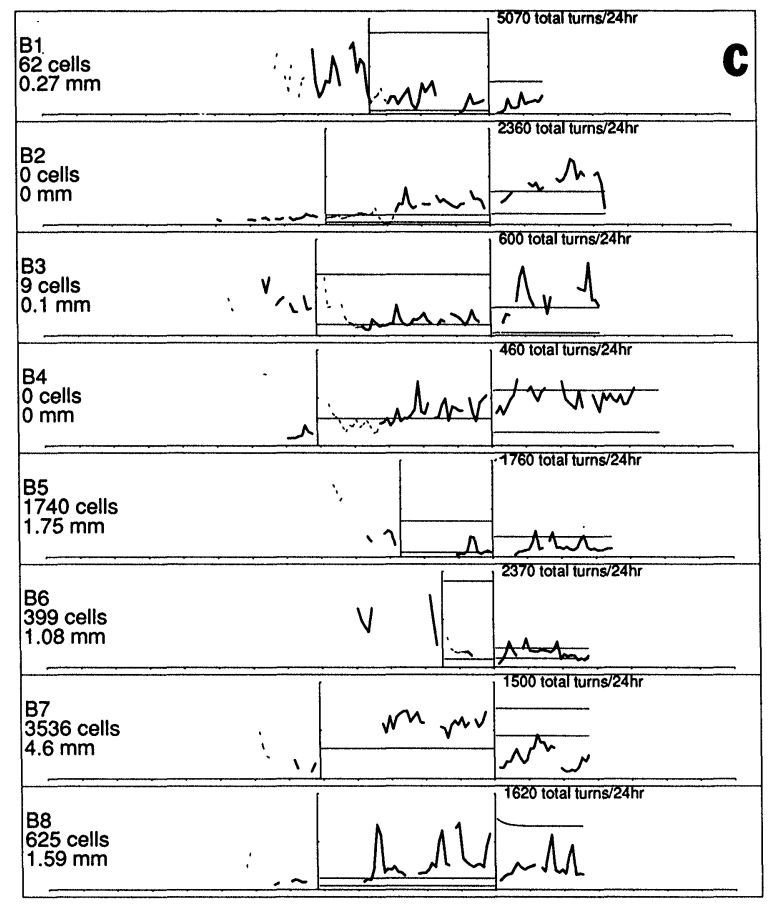

Fig. 2:

a. Turning preference: Like Fig. 1a, for monkeys $B 1-B 8$, which received grafts in the form of minced or diced tissue (B1-B4) or grafts prepared by an early, less successful version of the ribbon method $/ 15 /$. Monkey $B 1$ responded to the lesion with a paradoxical increase in contralateral turning preference. Monkey $\mathrm{B} 2$ received a second 6-OHDA treatment at $8 \mu \mathrm{g} / \mu \mathrm{l}$ (arrow).

b. Contralateral turns: Like Fig. $1 \mathrm{~b}$, for monkeys B1-B8.

c. Total activity: Like Fig. 1c, for monkeys B1-B8. 


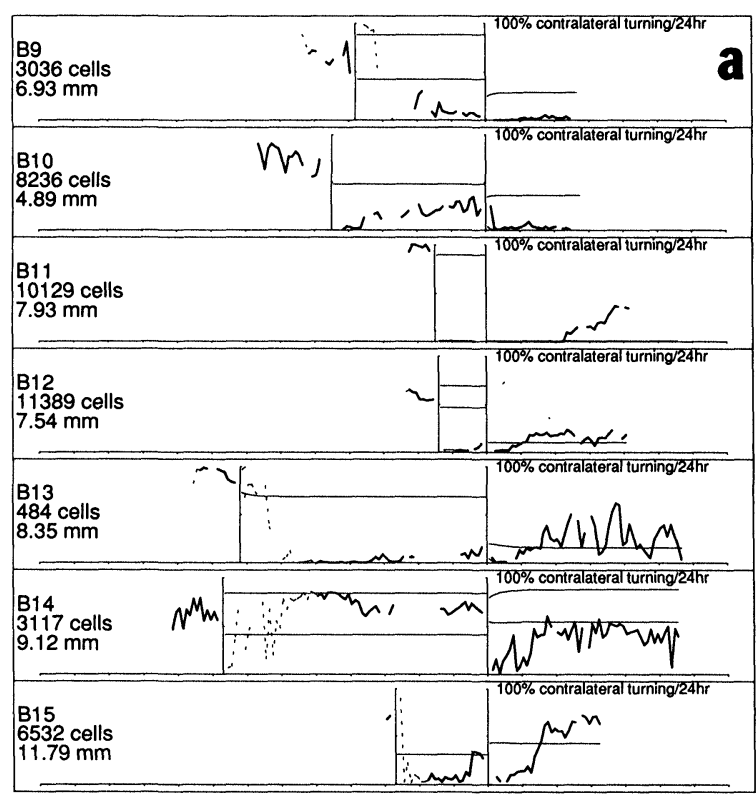

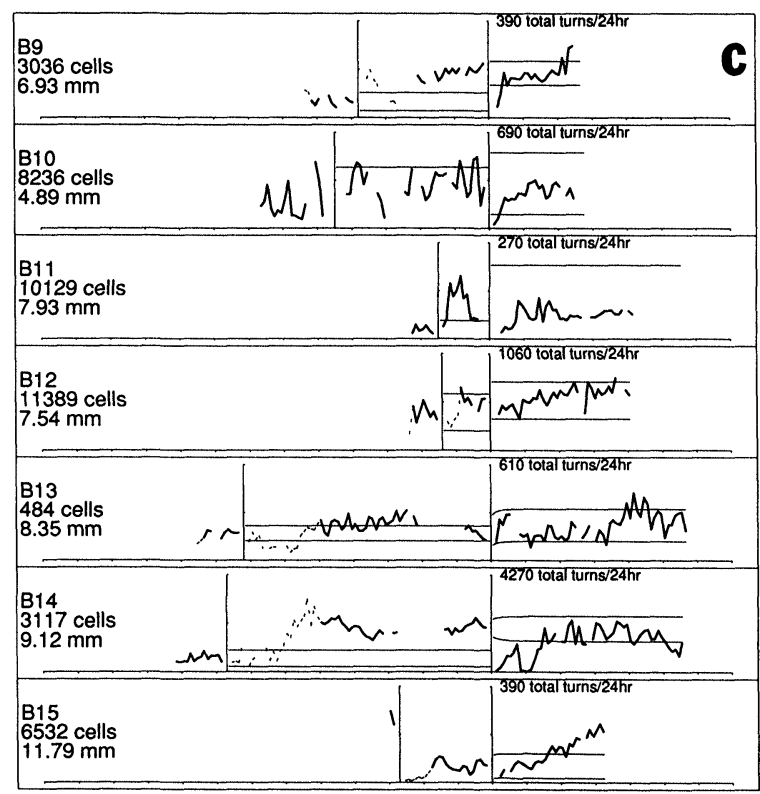

ribbon grafts produced a significantly greater improvement of turning preference than non-ribbon surgery controls $(p=0.021)$.

\section{Alternative Definition of Turning}

Event data collected for monkeys B1-B15 (but not for A1-A9) permit a comparison of results as

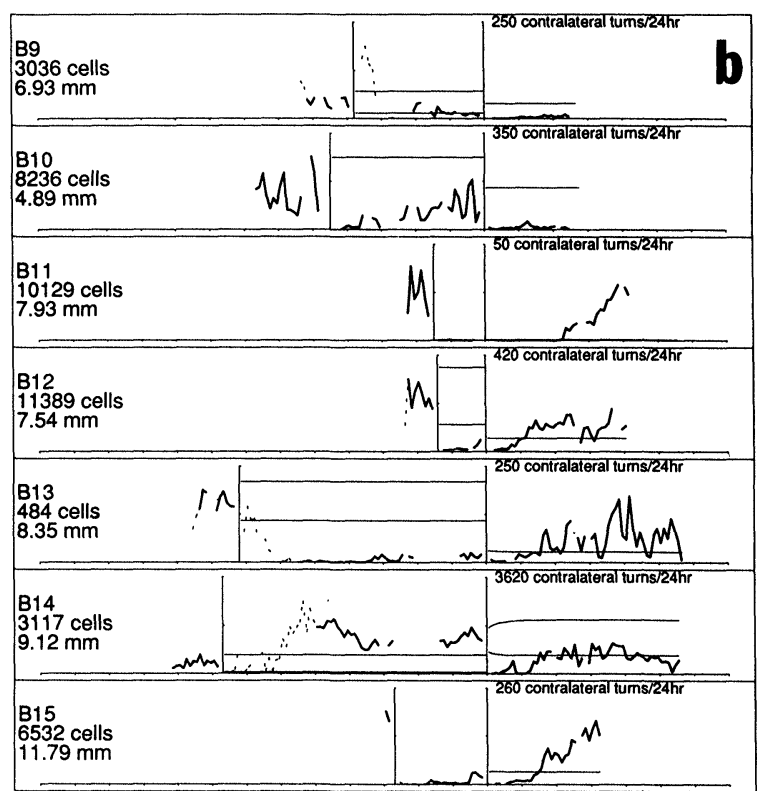

Fig. 3:

a. Turning preference: Like Fig. 1a, for monkeys B9-B15, which received ribbon grafts $/ 11,15 /$. Monkey B14 responded to the lesion with a paradoxical increase in contralateral turning preference; thus, the effect of the graft was uninterpretable.

b. Contralateral turns: Like Fig. 1b, for monkeys B9-B15.

c.Total activity: Like Fig. 1c, for monkeys B9-B15. assessed by the QD definition and by the $4 \mathrm{QF}$ definition, which simulates a definition commonly used in the rodent literature /34/. Event data for B1-B15 re-analyzed using this definition (Fig. 4-5) showed that in most cases, results were very similar in pattern, although total activity and number of contralateral turns were substantially lower as measured by $4 \mathrm{QF}$. 

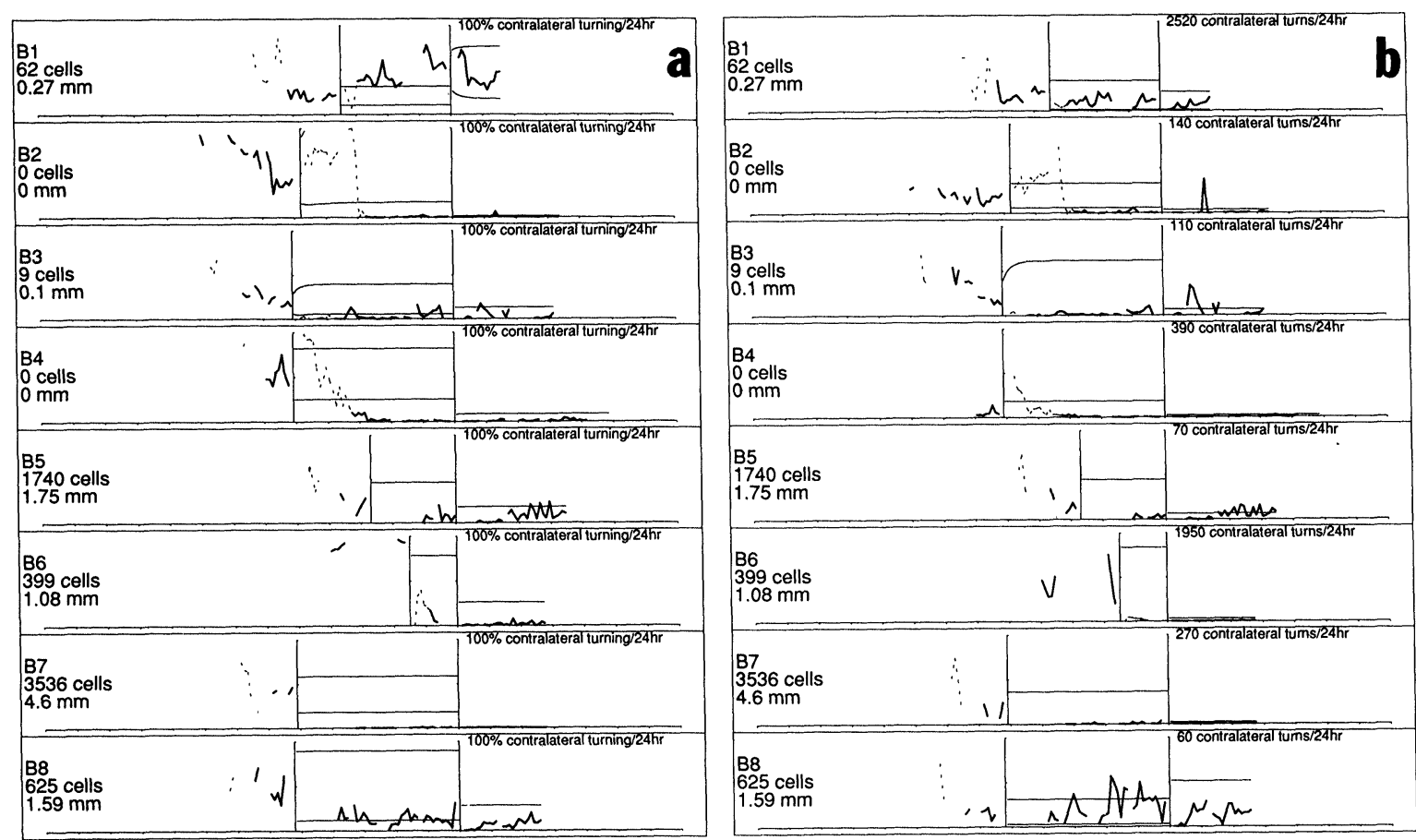

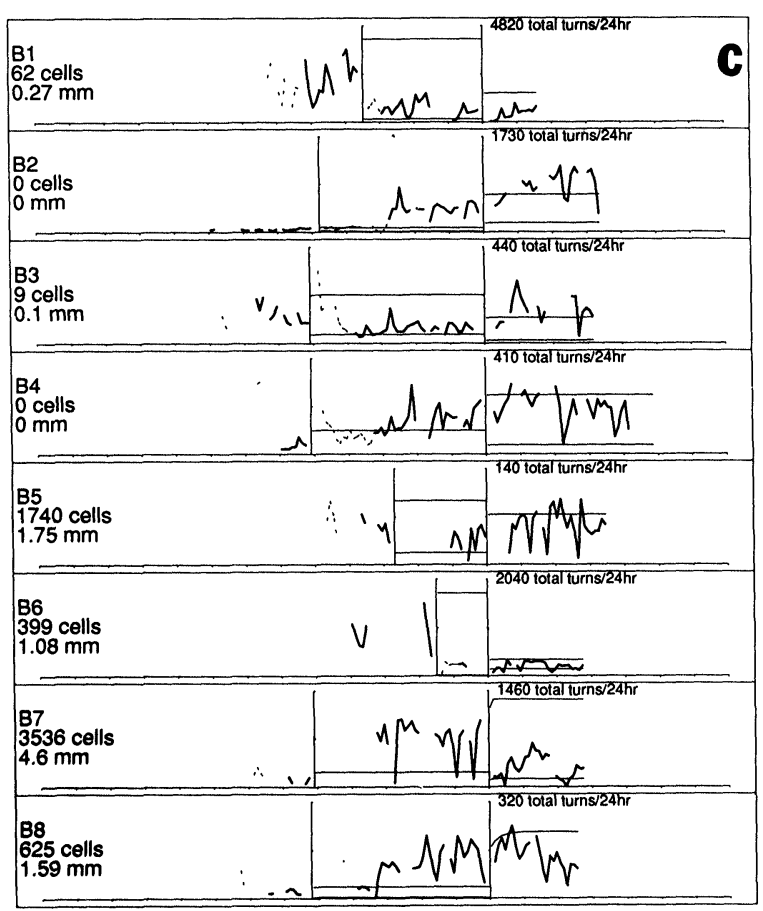

Fig. 4:

a. Turning preference: Like Fig. 2a, except that all data were based on the 4 QF definition of a turn. These and the other charts of Fig. 4-5 illustrate the similarity between data based on the two types of definition. For $\mathrm{B} 5, \mathrm{~B} 7$, and $\mathrm{B} 8$, one data point present in the $\mathrm{QD}$ analysis was lost because of an intervening hardware failure (the days 44,22 , and 16 days after the transplant, respectively).

b. Contralateral turns: Like Fig. 2b, but based on the $4 Q F$ definition of a turn.

c. Total activity: Like Fig. 2c, but based on the 4QF definition of a turn. 

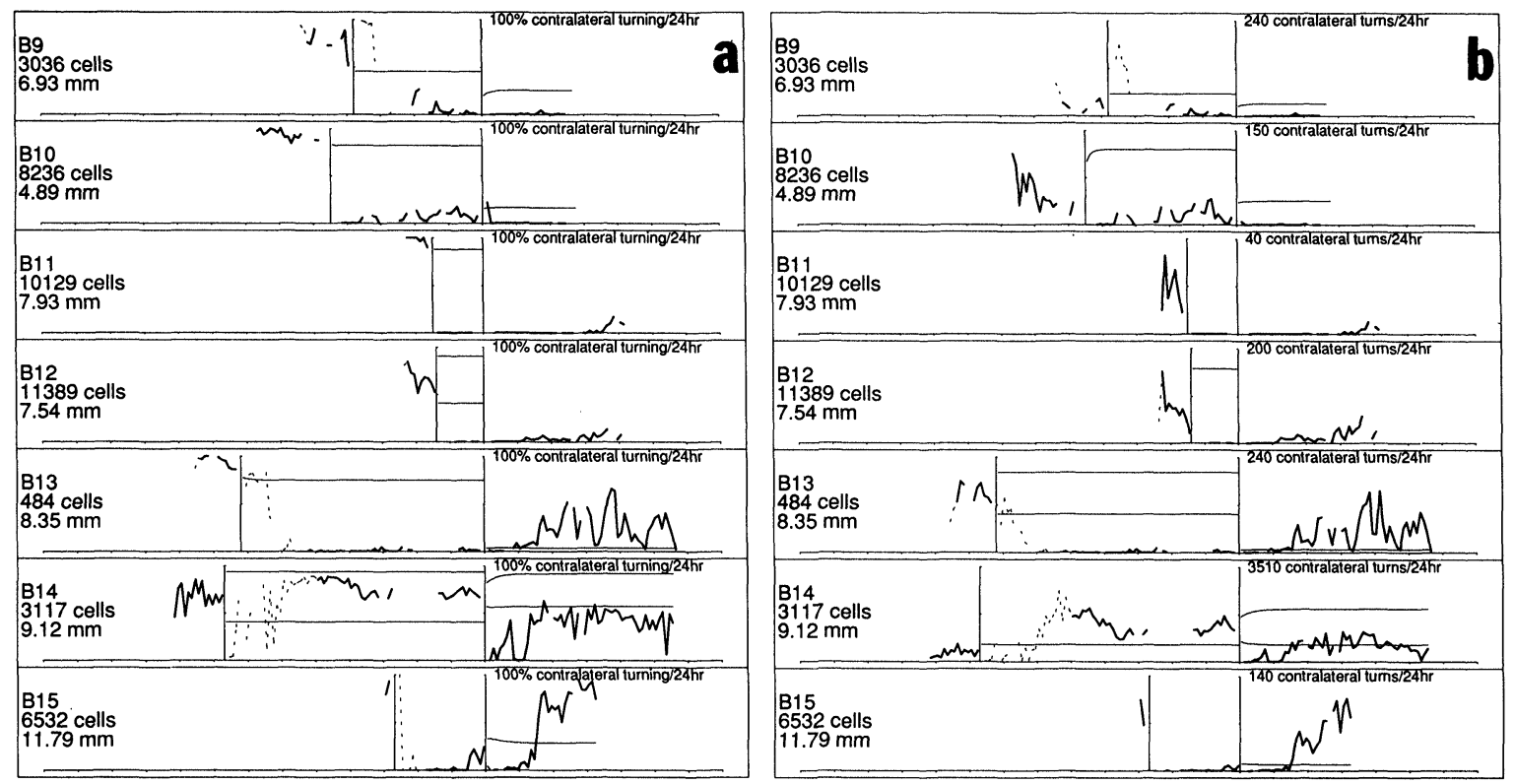

\begin{tabular}{|l|l|l|l|l|l|}
\hline B9 \\
3036 cells \\
$6.93 \mathrm{~mm}$
\end{tabular}

Fig. 5:

a. Turning preference: Like Fig. $4 \mathrm{a}$, but for monkeys B9-B15, showing effects of ribbon grafts on the basis of the $4 Q F$ definition, to be compared with the QD definition of Fig. 3a. For B10, one data point present in the QD analysis (5 days before the lesion) was lost because of an intervening hardware failure.

b. Contralateral turns: Like Fig. $4 b$, but for monkeys B9-B15.

C. Total activity: Like Fig. 4c, but for monkeys B9-B15.

\section{Apomorphine Effects}

ber of contralateral turns at least two standard deviations above the pretreatment mean for one or more of six 9-min intervals during the hour after injection. The rate of turning in response to apoinorphine, although often several times its 
pretreatment value, was never high (maximally about 1.7 turns/min). Turning preference and total activity were also elevated for a majority of these intervals, but these results were less consistent.

Data from one trial in each of six monkeys (A1, A9, B1-B4) given apomorphine more than one week before the 6-OHDA lesion showed no effects (example: A9, Fig. 6a-c). An examination of summed data from daily 24 -hour intervals before and after treatments gave no reason to suspect long-term effects of apomorphine administration.

\section{Amphetamine Effects}

After a low dose $(0.25 \mathrm{mg} / \mathrm{kg}$ i.m. $)$ of amphetamine in four monkeys (B1-B4), either before or 1-3 weeks after the 6-OHDA lesion, total activity was either sharply decreased or left unchanged (Fig. 7a-c). Activity was moderately increased for one intact monkey (B4) and one with a lesion (B2). In the lesioned monkey, turning in the contralateral direction was unaffected. As in the case of apomorphine, 24-h data gave no indication of long-term effects of amphetamine.
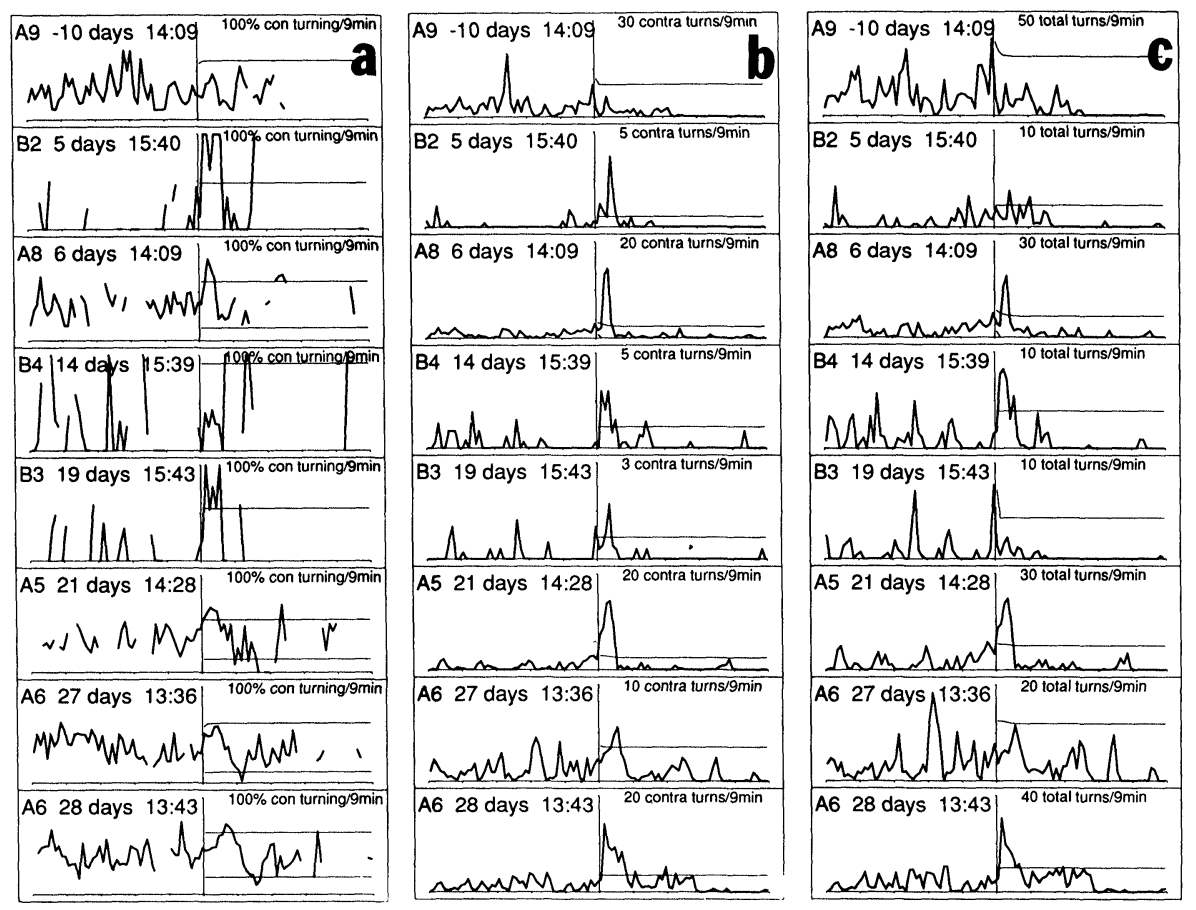

Fig. 6: a. Turning preference: Like Fig. 1a, but for apomorphine trials $(0.2 \mathrm{mg} / \mathrm{kg}$ i.m.) for the monkeys designated in the label to the left of each chart. Time intervals were $9 \mathrm{~min}$ rather than $24 \mathrm{~h}$; one division on the x-axis represents 10 intervals $=90 \mathrm{~min}$, and $y$-axis intersects $x$-axis at time of treatment. Label to the upper left indicates how many days had passed since the day of the 6-OHDA lesion (or, if negative, how many days before the lesion), and the time of day of the treatment. Animals were treated in their home cages, without visual contact with other animals, and the person administering treatment left the room immediately afterward. Percent data had erratic values for intervals with little activity. Intervals without activity were left blank and were not considered in ARIMA modeling.

b. Contralateral turns: Like Fig. $6 a$.

c. Total activity: Like Fig. $6 a$. 

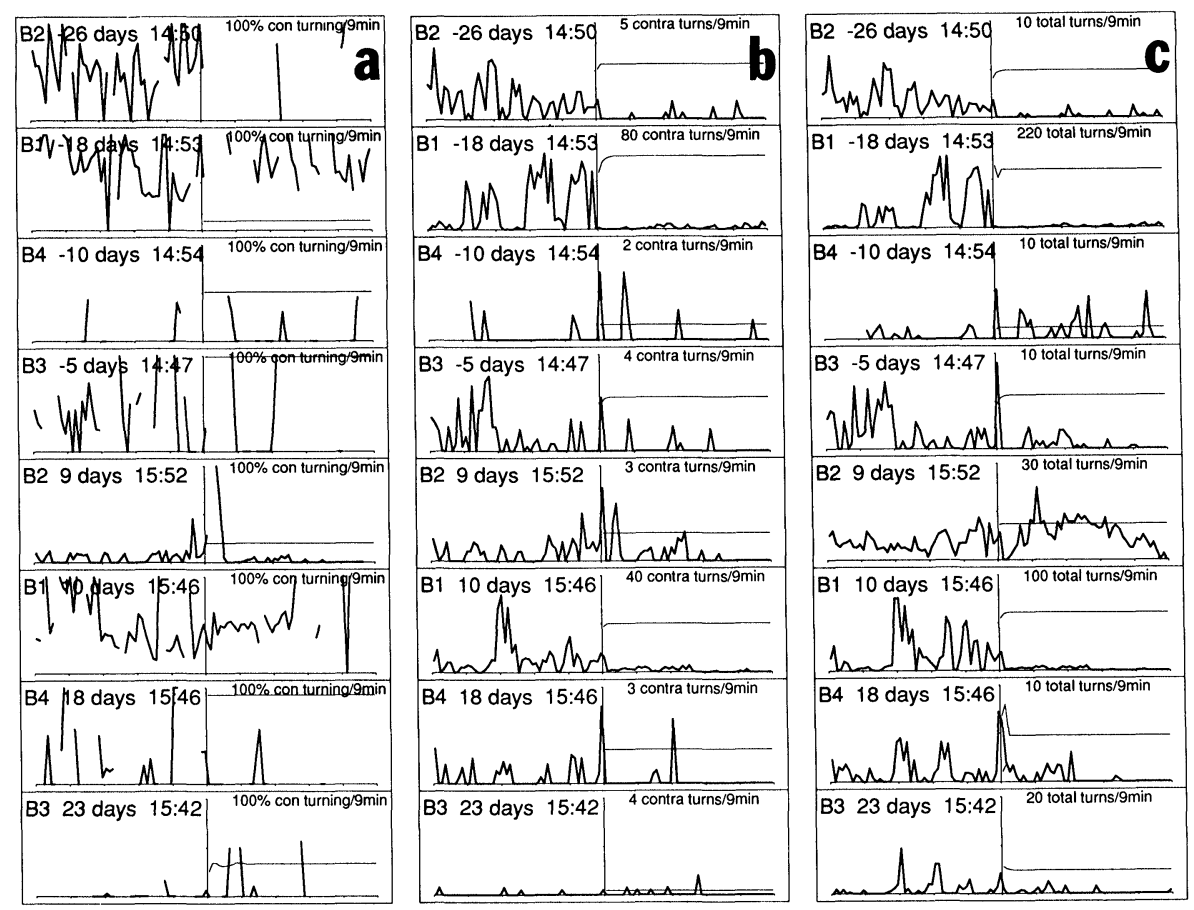

Fig. 7: a. Turning preference: Like Fig. $6 a$, for amphetamine trials.

b. Contralateral turns: Like Fig. 6b, for amphetamine trials.

c. Total activity: Like Fig. 6c, for amphetamine trials.

\section{DISCUSSION}

There is a great distance between the experimental observation that grafted fetal DA neurons can partially restore a normal response to apomorphine in rats with 6-OHDA lesions and the clinical application of DA implants as a practical treatment for Parkinson's disease. The $s_{p}$ : cies difference between the rat and the human is vast, the size of the striatum differs by $>100$-fold, the availability of both fetal nigral and autologous adrenal tissue is quantitatively different, the acute apomorphine behavioral assay differs from the chronic spontaneous human behavior one would wish to influence, and rotometric behavior itself differs from the full panoply of clinical symptoms of Parkinson's disease.

In previous studies, I have spanned some of the distance between the rodent model and the clinical application by 1 ) using a primate species that is more appropriate than a rodent species as a clinical model; 2) showing that tissue from an inexpensive, readily available experimental source, the autologous adrenal gland, is viable as a brain graft; 3 ) showing that this tissue can survive in the brain parenchyma, so that its influence can be spread throughout the striatum in a large primate brain, and 4) introducing and improving a distributed stereotaxic ribbon technique for grafting this tissue.

The present study extends those findings. It shows that (1) quantitative 24-h rotometry provides an appropriate behavioral model; (2) time series analysis can be effectively applied to evaluate tests of developing grafting techniques and graft placement, which inevitably take the form of case studies; (3) spontaneous turning preference is fairly consistent in a given intact monkey and is altered by unilateral 6-OHDA injections into the substantia nigra; (4) viable adrenal medullary ribbon grafts, if widely distributed in the striatum, appear to oppose this lesion effect. 


\section{(1) Behavioral Model: 24-h Rotometry}

Turning preference has been defined in this report as contralateral turning taken as a percentage of total turning. So defined, it is a measure independent of total activity. Alternative definitions applied in rodent studies include the number of contralateral turns $/ 22 /$, and the net contralateral turns $/ 18,33 /$. Each of those measures has also been applied in non-human primate studies $/ 26,37 /$. Neither is independent of total activity, which is highly variable among individuals; base-line data described above indicate that percent contralateral turning is a much more stable measure for a given monkey. The other alternatives are appropriate for models in which a stimulant drug in an animal with a unilateral lesion generates a reliably high level of activity and a unilateral turning preference approaching $100 \%$. For 24-h spontaneous turning in non-human primates, however, contralateral turning as a percentage of total turning is a much more useful measure because it excludes the influence of total activity. Percent contralateral turning is also somewhat more reliably affected by the lesion than number of contralateral turns, and total activity shows no predictable response to the lesion. Turning preference as defined in this report is therefore a valid as well as a reliable measure of the behavioral effects of the lesion, and is therefore a good measure for the reversal of lesion effects by transplants.

Another aspect of measurement concerns the definition of "turn". The fine-grained data stream from the optical encoder, together with the permanent record of small-scale "events", make it possible to apply retrospectively virtually any desired definition of a "turn", without the limitations imposed by other forms of instrumentation. A common definition in the rodent literature involves incrementing a full-turn count each time four consecutive quarter-turn boundaries are passed /34/. The system of dynamic boundaries described above was considered more faithful to the data at the outset of this project, and quarter turns were considered more likely to measure total activity and turning preference in monkeys with low spontaneous activity levels. Comparison of the two methods (Fig. 2-3 and Fig. 4-5) indi- cated that results were qualitatively similar. Dynamic boundaries, which account for the full sweep of each turn above criterion, can be applied with a full-turn criterion as well as with a quarterturn criterion. For more active monkeys that have visual contact with conspecifics, this may prove the best measure of turning preference and also a good measure of total activity.

\section{(2) Time series Analysis}

Because of the species, time and expense involved, the development of implant techniques in non-human primates requires that each variation of surgical method be tested in a very small number of animals. Each animal, in effect a case study, must serve as its own control in a before-vs-after design. In such a design, daily data points are intervals in a time series. Any autocorrelations within such data sets prevent the valid application of an individual t-test to each set, and require a time series analysis $/ 21 /$. The time series analysis of the present data was descriptive in nature. Inspection of the plots strongly suggests that lesions significantly decreased contralateral turning preference and that ribbon grafts were more effective in reversing this influence than surgical controls. T-tests comparing the means among subjects before and after treatments confirmed these impressions. This confirmation indicates the descriptive validity and usefulness of time series analysis.

With pre- and post-treatment series of suitable length, and with $a$ priori knowledge of the onset time of treatment effects, ARIMA is also capable of providing intervention analysis, which can estimate a significance level for data subsequent to a treatment $/ 21,39 /$. The onset time of lesion and transplant effects can be estimated for future experiments on the basis of these data. Time series analysis can therefore serve the need to test the hypothesis that a specific transplant technique and distribution of grafted tissue will have the desired effect on turning preference in an animal with a lesion.

\section{(3) Lesion Effects}

Lesions induced by 6-OHDA clearly had the 
intended effect on turning preference in most monkeys, namely a decrease in turning contralateral to the side of the lesion. Within subjects, the severity of the effect seemed stable within a period of three weeks, although varying responses were seen before stability was established. Neither pre-lesion preference nor pre-lesion total activity was a good predictor of lesion severity. Once established, the stability of turning preference for as long as 5-7 weeks supports its use as a model for transplant effects; recoveries were not observed prior to transplantation. These data indicate that four weeks should be allowed for stabilization of lesion effects; an additional eight weeks should be allowed for the determination of a reasonable time series model, before an implant is made.

Among individuals, severity varied widely; mean turning preference as a percentage of prelesion preference changed as little as $15 \%$ to more than $95 \%$. In addition, for about $20 \%$ of all monkeys lesioned, only two of which were used for adrenal grafts, a paradoxical increase in contralateral turning followed the lesion, and for $10 \%$, no change occurred. Animals with no response or a paradoxical response four weeks after the lesion should not be used for further studies of graft effects on behavior.

Variability and paradoxical turning are not uniquely related either to the longtailed macaque or to spontaneous 24-h turning. The results are qualitatively similar to results of 6-OHDA lesions in rodents. A $95 \%$ reduction of striatal DA is necessary for full behavioral effects in rodents $135 /$, and subjects are therefore routinely screened to select the more severely lesioned animals for further experimentation. In rodents with slightly less complete lesions, paradoxical turning has been observed in individuals in response to amphetamine /28/. Behavioral effects and DA terminal loss are accompanied in rodents by a corresponding loss of most midbrain DA neurons 17/. Plots of surviving TH-positive cells from sections throughout the substantia nigra have therefore been made for fourteen monkeys (A1, A3, $\mathrm{A} 5, \mathrm{~A} 6$, and B3-B12); preliminary data show no correlation between severity and the average number of surviving midbrain cells. A spatial analysis of surviving cells yet to be completed may indicate whether the distribution of midbrain cell loss is related to severity of the effect on turning preference. Qualitative comparison of striatal tissue ipsilateral and contralateral to the lesions indicated a large difference in terminal staining $/ 14 /$, but quantitative immunohistochemical comparisons among monkey were not feasible.

Responses to apomorphine were also qualitatively similar to those seen in rodents tested with 6-OHDA, but they were quantitatively much milder. The rate of contralateral turning was maximally about 1.7 turns/min, much smaller than normally observed in rats ( $>7$ turns/min $/ 19 /)$. The difference from rodent data might be attributed to a species difference; data from rhesus monkeys lesioned with intracarotid MPTP indicated about 7 turns/min /26/, 4.75 turns/min $/ 2 /$, and 3-4 turns/min $/ 37 /$. The one reported test of longtailed macaques lesioned by the intracarotid MPTP method gave an average rate (1.4-2.6 turns/min) somewhat closer to the maximum reported here $/ 8 \%$. The low magnitude of the response to apomorphine may be due to surviving DA neurons, but a direct comparison of neurotoxic and behavioral effects of the 6-OHDA and MPTP methods has not been made. Other factors not yet investigated in monkeys may have also played a role, such as the young age and size of the subjects $(2-5 \mathrm{yrs}, 2-3.5 \mathrm{~kg})$, the fact that they were exposed to apomorphine no more than three times, their visual isolation from other monkeys, or the size, shape, and familiarity of the home cages.

It is also possible that the intracerebral 6OHDA method has more nonspecific deleterious effects on cells in the substantia nigra of monkeys than rats, thus decreasing the possibility of a robust response to apomorphine. Lesions in rodents that do not selectively destroy dopaminergic cells - electrolytic, kainic acid, and cooling treatments - all increase, rather than decrease, contralateral turning in response to apomorphine 127/. It is possible that a varying amount of nonspecific damage widened the range of effects on spontaneous turning preference and lowered the magnitude of the apomorphine response.

A low dose of amphetamine had no effect on turning preference, and was more often followed by a decrease than by an increase of total activity. 
Although this treatment normally increases total activity in unilaterally lesioned rats, favoring ipsilateral turning, this may not be the case for primates, depending on the environmental setting. In humans in a quiet, clinical setting, a low dose of amphetamine has been found to have a quieting effect on many subjects $/ 32 /$.

\section{(4) Transplant Effects}

Ribbon grafts in most cases appeared to ameliorate the effect of the lesion on turning preference. The four monkeys that improved with the ribbon grafts $(\mathrm{B} 11, \mathrm{~B} 12, \mathrm{~B} 13$, and $\mathrm{B} 15)$ had the greatest total lengths of viable graft, and the monkey with a return to base line (B15) had a greater total length than the other three, the greatest number of separate tracks showing viable tissue, and the largest set of viable grafts in the putamen (Dubach /12/: Table 3). Putamen grafts in other monkeys, unlike those in B15, were concentrated dorsomedially, near the internal capsule. The presence of grafts at several points in the putamen as well as the caudate may be required for maximal effect. The two monkeys that received ribbon grafts without increasing contralateral turning (B9 and B10) had the smallest total lengths of surviving tissue, although one of these monkeys had a high total number of cells. Taken together, these data suggest that for the restoration of spontaneous turning after a 6OHDA lesion, the best graft treatment is the one that reaches the widest three-dimensional volume in the caudate and putamen. Since half the grafts in B13 and all the grafts in B15 were half the width of other ribbon grafts, it also suggests that narrow grafts are as effective as thick grafts. This is consistent with the proposition that catecholamine diffusing from the surface of the graft into adjoining host tissue is responsible for the effect on turning preference.

Other behavioral studies of adrenal grafts in monkeys have used surgical methods very different from those of the present study. Behavioral data have been reported for a total of 16 other non-human primate subjects that have received adrenal grafts $/ 3,26,37 /$. Lesions were made in these monkeys by the unilateral intracarotid injection of MPTP /1/. Grafts were placed in cavities on the ventricular surface of the caudate nucleus after an open transcortical or transcallosal approach, similar to the human surgery introduced by Madrazo et al. $/ 23 /$. Of these 16 subjects, $6 \mathrm{had}$ no chromaffin cells demonstrably viable at necropsy /3, 26/, 2 had unspecified low numbers of cells described as "a thin rim" or "small rests" /26/, and 8 had unspecified numbers of cells described as "less than $3 \%$ of the estimated total number grafted" $137 /$. Improvements in rotational response to apomorphine were observed in each study, regardless of the number of viable cells. One group of investigators attributed recovery to the sprouting of host dopaminergic fibers induced by the surgery $/ 3 /$, rather than to the transplant. In the extensive rodent literature, behavioral effects are most often attributed to the release of catecholamines by viable graft cells $/ 19 /$.

This is the first primate study in which behavioral effects attributable to viable adrenal medullary grafts in the caudate and putamen parenchyma have been reported. Ribbon grafts, especially if well-distributed within the striatum, show an encouraging tendency to reverse the effect of a unilateral nigral lesion on turning preference. The stereotaxic method does not involve the massive caudate lesion involved in previous primate studies, and no evidence of host sprouting has been observed in these subjects. These results lend support to the concept suggested in the one behavioral report that involved the survival of significant amounts of graft tissue in monkeys $/ 37 /$, that the graft effects were related to surviving chromaffin cells.

\section{ACKNOWLEDGEMENTS}

I wish to thank the Bioengineering Division of the Regional Primate Research Center for assistance in designing and building rotometry equipment, and other members of the Primate Center staff for animal care and veterinary services. Iohexol for ventriculography was kindly provided by the Sterling-Winthrop Research Institute (Rensselaer, NY). Support for this work came in part from NIH grant RR00166 to the University of Washington Regional Primate Research Center, and primarily from NIH (NINDS) grant RO1 NS25724 for Neuron Transplant Therapy. 


\section{REFERENCES}

1. Bankiewicz KS, Oldfield EH, Chiueh CC, Doppman JL, Jacobowitz DM, Kopin IJ. Hemiparkinsonism in monkeys after unilateral internal carotid artery infusion of 1-methyl-4-phenyl-1,2,3,6-tetrahydropyridine (MPTP). Life Sci 1986; 39: 7-16.

2. Bankiewicz KS, Plunkett RJ, Jacobowitz DM, Porrino L, di Porzio U, London WT, Kopin IJ, Oldfield EH. The effect of fetal mesencephalon implants on primate MPTP-induced parkinsonism. Histochemical and behavioral studies. J Neurosurg 1990; 72: 231-244.

3. Bankiewicz KS, Plunkett RJ, Kopin IJ, Jacobowitz DM, London WT, Oldfield EH. Transient behavioral recovery in hemiparkinsonian primates after adrenal medullary allografts. Prog Brain Res 1988; 78: 543549.

4. Bjorklund A, Stenevi U. Reconstruction of the nigrostriatal dopamine pathway by intracerebral nigral transplants. Brain Res 1979; 177: 555-560.

5. Box GEP, Jenkins GM. Time series analysis: Forecasting and control. San Francisco: Holden Day, 1970; 553pp.

6. Bracha HS, Shults C, Glick SD, Kleinman JE. Spontaneous asymmetric circling behavior in hemi-parkinsonism; A human equivalent of the lesioned-circling rodent behavior. Life Sci 1987; 40: 1127-1130.

7. Buonamici M, Cervini MA, Rossi AC, Sebastiani L, Raffaelli A, Bagnoli P. Injections of 6hydroxydopamine in the substantia nigra of the rat brain: morphological and biochemical effects. Behav Brain Res 1990; 38: 83-95.

8. Clark CE, Boyce S, Robertson RG, Sambrook MA, Crossman AR. Drug-induced dyskinesia in primates rendered hemiparkinsonian by intracarotid administration of 1-methyl-4-phenyl-1,2,3,6tetrahydropyridine (MPTP). J Neurol Sci 1989; 90: 307-314.

9. Crossman AR, Sambrook MA. Experimental torticollis in the monkey produced by unilateral 6hydroxydopamine brain lesions. Brain Res 1978; 149: 498-502.

10. Dooley DJ, Dubach MF, Blake PH, Bowden DM. A chronic, stereotaxic guide-tube platform for intracranial injections in macaques. J Neurosci Meth 1981; 3: 385-396.

11. Dubach M. Adrenal medulla "ribbon" grafts in nonhuman primates: Transplant methods. J Neurosci Meth 1991; 39: 19-28.

12. Dubach M. Viable adrenal medullary transplants in non-human primates: Increasing the number of grafts. J Neur Transplant Plast 1992; 3: 81-96.

13. Dubach $M$. A rotometry method for nonhuman primates, and single-subject evaluation by time series analysis. 1992; in preparation.

14. Dubach M, Schmidt RH, Martin R, German DC, Bowden DM. Transplant improves hemiparkinsonian syndrome in nonhuman primate: intracerebral injec- tion, rotometry, TH-immunohistochemistry. Prog Brain Res 1988; 78: 491-496.

15. Dubach M, German DC. Extensive survival of chromaffin cells in adrenal medulla "ribbon" grafts in monkey neostriatum. Exp Neurol 1990; 110: 167-180.

16. Dunnett SB, Bjorklund A, Stenevi U. Transplant-induced recovery from brain lesions: A review of the nigrostriatal model. In: Wallace RB and Das GD, eds, Neural Tissue Transplantation Research. New York Berlin Heidelberg Tokyo: Springer-Verlag, 1983; pp. 191-216.

17. Dunnett SB, Bjorklund A, Stenevi U, Iverson SD. Behavioral recovery following transplantation of substantia nigra in rats subjected to 6-OHDA lesions of the nigrostriatal pathway. I. Unilateral lesions. Brain Res 1981; 215: 147-161.

18. Dunnett SB, Hernandez TD, Summerfield A, Jones GH, Arbuthnott G. Graft-derived recovery from 6OHDA lesions: specificity of ventral mesencephalic graft tissues. Exp Brain Res 1988; 71: 411-424.

19. Freed WJ, Functional brain tissue transplantation: reversal of lesion-induced rotation by intraventricular substantia nigra and adrenal medulla grafts, with a note on intracranial retinal grafts. Biol Psychiat 1983; 18: 1205-1267.

20. Freed WJ, Perlow MJ, Karoum F, Seiger A, Olson L, Hoffer BJ, Wyatt RJ. Restoration of dopaminergic function by grafting of fetal rat substantia nigra to the caudate nucleus: Long-term behavioral, biochemical, and histochemical studies. Ann Neurol 1979; 8: 510519.

21. Glass GV, Willson VL, Gottmann JM. Design and analysis of time-series experiments. Boulder CO: Colorado Associated Press, 1975; 241 pp.

22. Herrera-Marschitz M, Ungerstedt U. Evidence that apomorphine and pergolide induce rotation in rats by different actions on D1 and D2 receptor sites. Eur $\mathbf{J}$ Pharm 1984; 98: 165-176.

23. Madrazo I, Drucker-Colin R, Diaz V, Martinez-Mata J, Torres C, Becerril JJ. Open microsurgical autograft of adrenal medulla to the right caudate nucleus in two patients with intractable Parkinson's disease. New Engl J Med 1987; 316: 831-834.

24. McCleary R, Hay RA. Applied time series analysis for the social sciences. Beverly Hills CA: Sage Publications, 1980; 331pp.

25. Morton WR, Knitter GH, Smith PM, Susor TG, Schmitt K. Alternatives to chronic restraint of nonhuman primates. J Am Vet Med Assoc 1987; 191: 1282-1289.

26. Plunkett RJ, Bankiewicz KS, Cummins AC, Miletich RS, Schwartz JP, Oldfield EH. Long-term evaluation of hemiparkinsonian monkeys after adrenal autografting or cavitation alone. J Neurosurg 1990; 73: 918-926.

27. Pycock CM. Turning behavior in animals. Neuroscience 1980; 5: 461-514.

28. Robinson TE, Becker JB. The rotational behavior 
model: asymmetry in the effects of unilateral 6-OHDA lesions of the substantia nigra in rats. Brain Res 1983; 264: 127-131.

29. SPSS Inc. SPSS/PC + Trends for the IBM PC/XT/AT and PS/2. Chicago IL: SPSS Inc, 1987; 300pp.

30. Schmidt RH, Dubach $M$. A computer-based rotation and activity monitor for non-human primates and other animals. J Neurosci Meth 1988; 24: 243-251.

31. Snedecor GW, Cochrane WG. Statistical methods. Ames IA: Iowa State University Press, 1989; 503pp.

32. Tecce JJ, Cole JO. Amphetamine effects in man: paradoxical drowsiness and lowered electrical brain activity (CNV). Science 1974; 185: 451-453.

33. Ungerstedt U. Postsynaptic supersensitivity after 6hydroxydopamine induced degeneration of the nigrostriatal dopamine system. Acta Physiol Scand Suppl $1971 ; 367: 49-68$.

34. Ungerstedt U, Avemo A, Avemo E, Ljungberg T, Ranje C. Animal models of parkinsonism. Adv Neurol 1973; 3: 257-271.

35. Ungerstedt U, Herrera-Marschitz M. Behavioural pharmacology of dopamine receptor mechanism. In: Stjarne L, Hedquist P, Lagercrantz $H$, Wennmalm A, eds, Chemical Neurotransmission: 75 Years. New York: Academic Press, 1981; pp. 481-494.

36. Viallet $F$, Trouche $E$, Nieoullon $A$, Beaubaton $D$, Legallet E. Unilateral electrolytic and 6-OHDA lesions of the substantia nigra in baboons: behavioral and biochemical data. Adv Behav Biol 1984; 27: 373391.

37. Watts RL, Bakay RAE, Herring CJ, Sweeney KM, Colbassani HJ, Mandir A, Byrd LD, Iuvone PM. Preliminary report on adrenal medullary grafting and cografting with sural nerve in the treatment of hemiparkinson monkeys. Prog Brain Res 1990; 82: 581-591.

38. Winn SR, Wahlberg L, Tresco PA, Aebischer P. An encapsulated dopamine-releasing polymer alleviates experimental parkinsonism in rats. Exp Neurol 1989; 105: 244-250.

39. Wei WWS. Time series analysis. Redwood City CA: Addison-Wesley Publ Co, 1990; 478pp. 

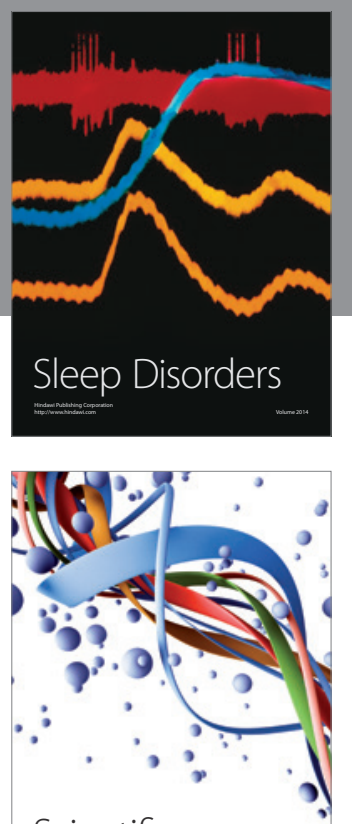

Scientifica
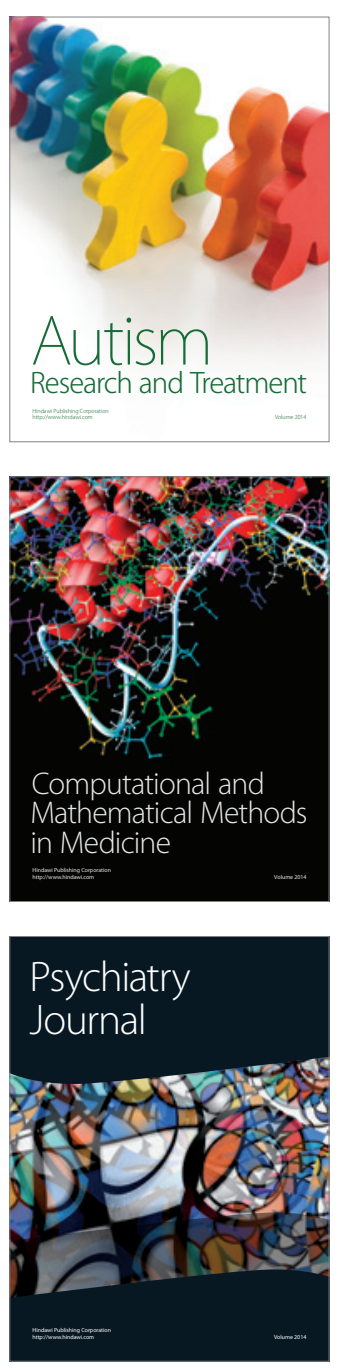
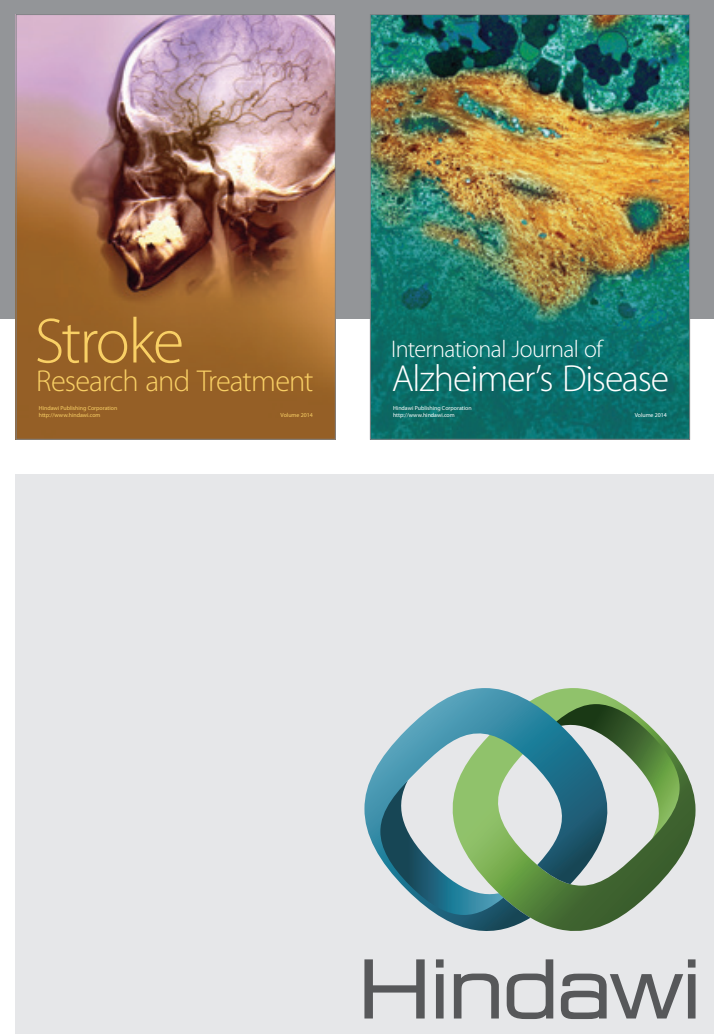

Submit your manuscripts at

http://www.hindawi.com
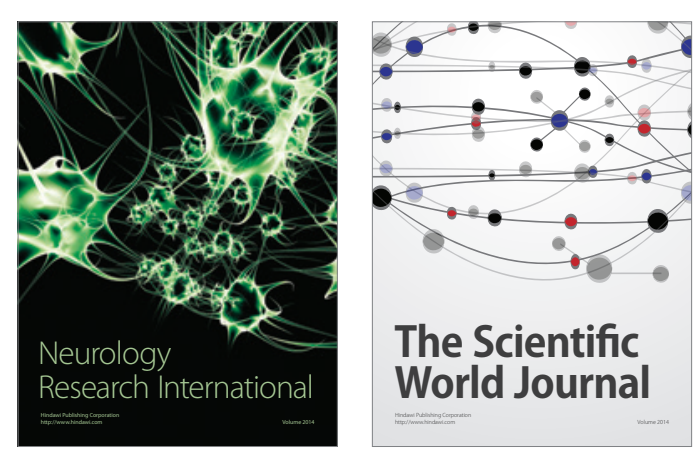

The Scientific World Journal

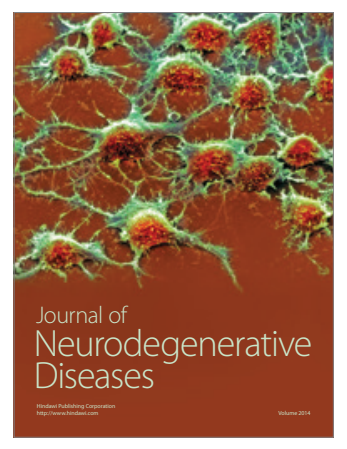

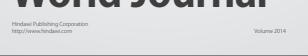

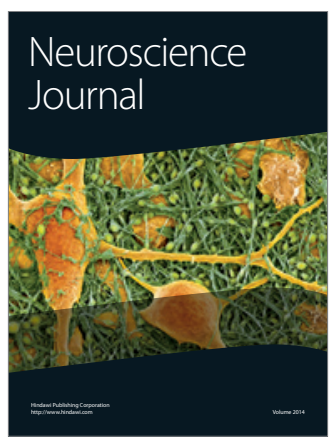

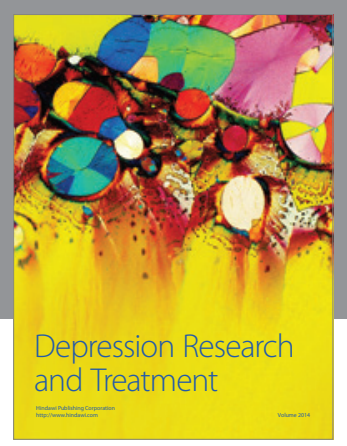
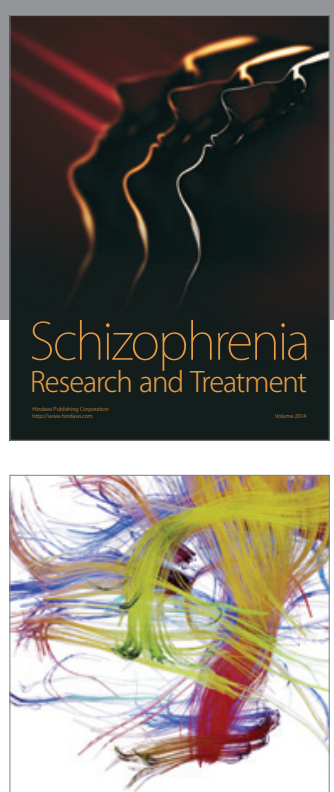

Brain Science

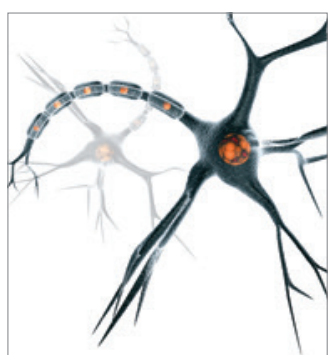

Neural Plasticity
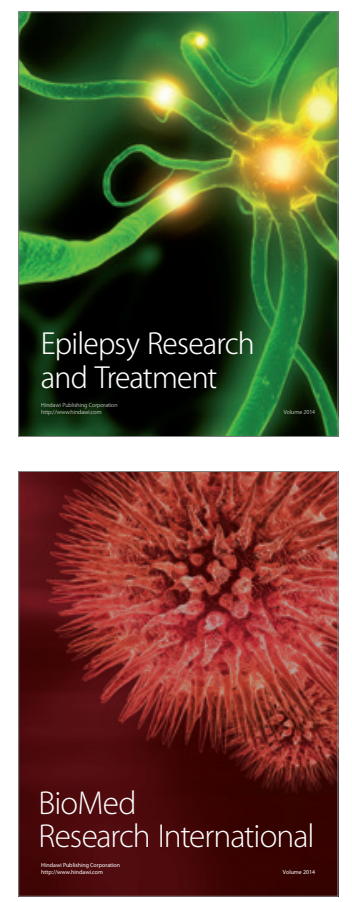

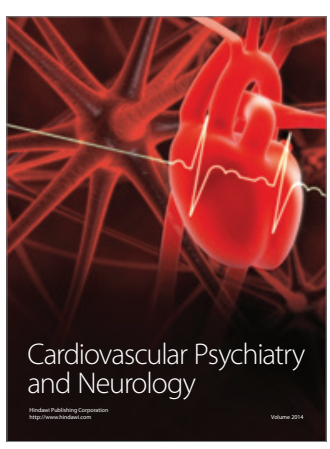

Parkinson's

Disease
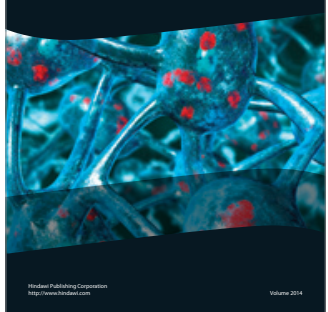